\title{
The Transformation and Updating of Service of Regional Industries Featured as "One Town-one Product-one Major"
}

\author{
Gen-rang ZHENG ${ }^{1}$ and Yi WEN ${ }^{2, *}$ \\ 'Zhongshan Polytechnic, Zhongshan City, Guangdong Province, China \\ 2Zhongshan Vocational, Zhongshan City, Guangdong Province, China \\ ${ }^{*}$ Corresponding author
}

Keywords: One town-one product-one major, Service, Regional industries, Transformation and updating.

\begin{abstract}
In order to improve the ability of major-serving for the regional industrial development, Zhongshan Polytechnic takes the major-serving for regional economic development as its research project, and has defined the outline of major developmnent. The college has also set up the cooperative education system of major-serving for regional industrial development, which has innovated its teaching management administration mode, enhanced the regional economic development, and improved the major-serving ablility for the industries.
\end{abstract}

\section{“一镇一品一专业”服务区域产业转型升级}

\author{
郑根让 ${ }^{1}$, 文怡 ${ }^{2, *}$ \\ 1中山职业技术学院, 广东省中山市, 中国 \\ 2中山市中等专业学校, 广东省中山市, 中国 \\ “通讯作者
}

关键词: 一镇一品一专业; 服务; 区域产业; 转型升级

摘要：为了提升高职院校专业服务区域产业发展能力, 中山职业技术学院以服务区域经济发 展为己任, 在专业镇转型升级中明确专业发展思路, 探索出专业服务区域产业发展的合作办 学体制, 创新了教育教学管理模式, 促进了区域产业发展, 提升了专业服务产业发展能力。

\section{1. 特色鲜明的专业镇经济}

20世纪90年代以来，珠江三角洲地区出现了大批经济规模超过几十亿甚至百亿元的产业 相对集中、产供销一体化、以镇级经济为单元的新型经济形态, 称之为专业镇经济, 属于经 济学界所谓的 “簇群经济”、“集群经济”、“专业产品区” 范畴, 其最显著的特征是小企 业、大产业、小产品、大市场。

\section{1 专业镇发展之 “专”}

中山市是广东省专业镇分布密度最大的地级市之一。中山专业镇产业领域涵盖灯饰、五 金、纺织服装、电梯、家电、家具、食品等传统产业, 同时还发展了LED、游戏游艺、节能 环保和文化旅游等战略性新兴产业, 目前拥有 15 个专业镇。全市 27 个国家级产业基地有 19 个 设在专业镇, 2011年专业镇完成地区生产总值超千亿元, 专业镇经济占据中山经济 “半壁江 山”。中山主要专业镇情况如表1所示。 
表1 中山市主要专业镇情况表

\begin{tabular}{|c|c|c|c|c|}
\hline 专业镇名称 & 相关企业数量 & 产值 (亿元) & 市场份额 & 从业人数 (人) \\
\hline 古镇灯饰专业镇 & 9760 & 170.8 & $62 \%$ & 79000 \\
\hline 南区电梯产业基地 & 40 & 110 & $20 \%$ & 6000 \\
\hline 港口游戏游艺专业镇 & 274 & 101 & $65 \%$ & 6700 \\
\hline 小榄五金制品专业镇 & 7630 & 203.1 & $40 \%$ & 38500 \\
\hline 大涌红木家具专业镇 & 600 & 80 & $60 \%$ & 31000 \\
\hline 沙溪休闲服装专业镇 & 732 & 178.2 & $30 \%$ & 73000 \\
\hline 东风小家电专业镇 & 432 & 98 & $20 \%$ & 43000 \\
\hline
\end{tabular}

中山在专业镇建设发展中探索出了一条“一镇一品”做强做精专业镇的特色发展之路, 专业镇经济和集群创新的蓬勃发展催生了一批如古镇灯饰、小榄五金、港口游艺设备等全国 市场占有率60\%以上，产值过百亿的特色鲜明、竞争力强的 “明星品牌专业镇” ，形成了一 批在国内外有一定影响的特色产业和产品。

\section{2 专业镇转型之 “惑”}

目前区域经济与产业结构迅速向技术、知识密集型转化，技术应用型人才的需求也日益 多元化, 部分传统的优势专业镇集群化产业受到极大的冲击。中山专业镇在快速发展的同时, 产业层次不高、技术水平不高、创新能力不强等问题也相继出现, 长期以来以镇为单位的产 业发展模式已显得捉襟见肘，专业镇转型升级势在必行。

经济发展过程中的压力往往会带来新的发展机遇, 一方面会促使传统产业创新改造升级, 以适应市场发展，同时也会 “催生”一批新兴产业，但无论是传统产业的改造升级还是新兴 产业的崛起, 都需要技术和人才的有力支持。高职院校作为本土大学, 在区域经济转型升级 中应义不容辞地充当主力军。

\section{2. 服务区域经济发展是高职教育的神圣使命}

\section{1 高职院校在专业镇经济发展中的关系及地位}

中山市直接管辖区镇, 是只有市镇两级行政设置的地级市, 高职教育与专业镇建设的互 动关系涉及了四方主体，即市级政府、区镇政府、企业和高职院校，其关系如图1所示。

市级政府为专业镇建设发展提供政策保障，协调各种关系，有效配置资源，同时规范、 优化专业镇发展宏观环境; 区镇政府为本地企业发展搭建合作和技术平台, 对企业进行评估 监督，促进企业健康、科学发展; 市政府为高职院校提供政策指引、资金支持和社会服务引 导，使高职院校更好地为本地经济和社会发展服务; 高职院校直接与专业镇合作，开展合作 办学、专业校企共建、信息交流、技术服务等，为专业镇长远发展提供智力支持; 高职院校 通过区镇政府为企业开展订单式人才培养、交流合作、技术改造等为企业提供专业服务。

专业镇建设中四方主体共同构成了专业镇建设发展的基石，当四方主体充分发挥各自的 功能, 协调发展就会为专业镇长远发展提供不竭动力。 


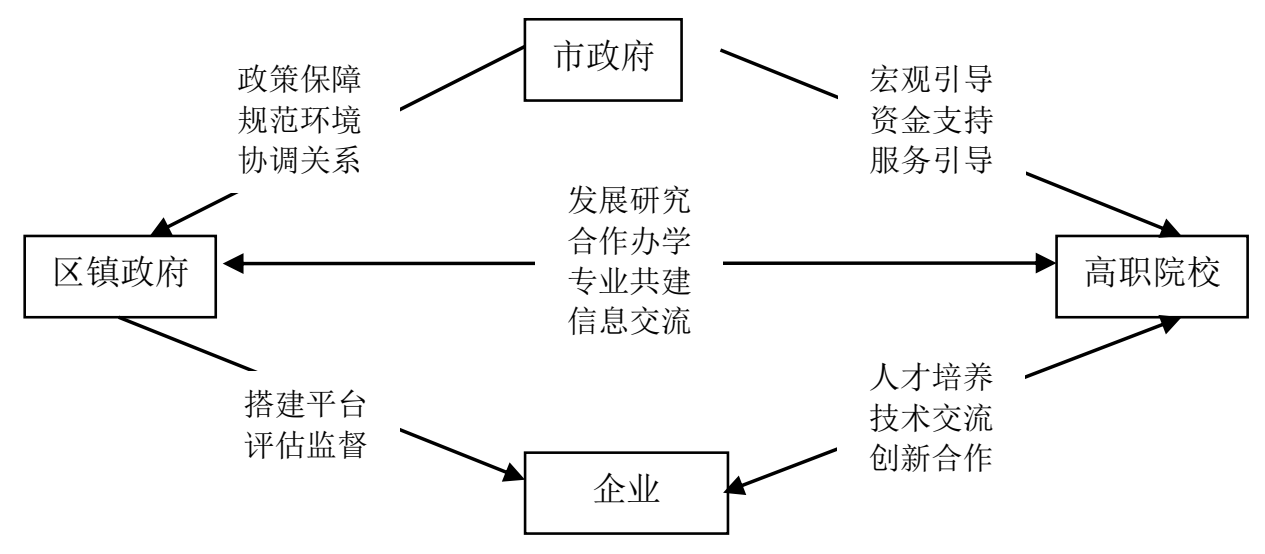

图1 市级政府、区镇政府、企业和高职院校关系图

\section{2 高职教育服务专业镇转型升级具有先天优势}

高等职业教育是直接为区域经济发展服务, 为地方企业培养应用型人才的教育形式。实 践证明高职教育是区域经济发展的 “助推器” , 高职教育在区域经济发展中具有专业人才培 养、发展思路创新、合作技术改造、员工培训服务、现代信息服务、区域文化提升等功能。

2.2.1 专业优势是高职服务专业镇建设发展之魂

高职教育不同于以学科建设为中心的本科教育，专业是高职院校的品牌和灵魂。高职院 校专业设置有较大的自主性和灵活性, 学校可以根据区域产业结构布局、产业结构调整和支 柱产业对人才需求, 设置、调整学校专业, 使高职专业结构与区域产业结构对接, 以促进区 域经济的发展。

2.2.2 区域优势是高职服务专业镇建设的立足之本

高职院校在与本地企业合作发展中，区域优势显著。首先，市级政府为高职院校发展提 供了政策和资金保障, 经济发达的专业镇为高职院校毕业生提供了广阔的就业市场; 其次, 区域优势在高职院校与镇级政府和企业实训基地共建、双师教师培养及合作交流等方面占据 了先机; 第三, 高职院校所具有的优越的区域文化优势使得人才培养更具本土化特色, 人才 培养适应了专业镇以中小企业为主，集群化经营为特色的专业镇经济。

2.2.3 需求优势是高职服务专业镇建设的动力之源

市场需求是高职院校长足发展的不竭动力。专业镇发展之初吸引了大批优秀人才到专业 镇创业发展, 随着专业镇的发展演变, 内地经济的崛起, 专业镇在人才政策方面的优势逐渐 丧失, 专业镇人才要由外地 “输血” 转向自身 “造血”。高职院校人才 “造血” 具有得天独 厚的优势, 具有本土优势的高职毕业生成为专业镇建设的中坚力量。范唯指出: “唯有高技 能人才很难流动, 就是因为他们有地域性的限制和顾虑” 。在新经济条件下, 高职院校在专 业镇转型升级中的助推器作用凸显。

\section{3. “一镇一品一专业” 服务专业镇经济}

\section{1 紧扣镇区产业发展, 谋划专业建设布局}

中山专业镇建设具有 “一镇一品” 的产业布局特色，中山职业技术学院坚持服务区域经 济发展的办学理念, 围绕镇区产业布局设置专业, 紧扣镇区产业发展建设专业。学院在深入 调研镇区产业发展规模、层次和人才需求规格、数量的基础上, 设置了包括灯具、电梯、服 装、动漫、家具等32个对接镇区产业的招生专业, 形成了与区域产业结构对应的 “一镇一品 一专业” 的专业结构布局。“一镇一品一专业” 与专业镇经济高度融合发展的特色办学之路 不仅为专业镇发展提供了智力、人才和信息支持，而且使学院专业建设日趋成熟。 
表 2 重点专业对应专业镇情况表

\begin{tabular}{|c|c|c|}
\hline 区镇名 & 对应产业 & 设置专业 \\
\hline 古镇镇 & 灯饰 & 灯具设计与制造 \\
\hline 南区 & 电梯 & 电梯工程技术 \\
\hline 小榄镇 & 五金 & 模具设计与制造 \\
\hline 沙溪镇 & 服装 & 服装设计 \\
\hline 大涌镇 & 红木家具 & 雕刻艺术与家具设计 \\
\hline 港口镇 & 游戏游艺 & 动漫设计与制作 \\
\hline 火炬区 & 电子信息 & 电子信息工程 \\
\hline 火炬区 & 装备制造 & 数控技术 \\
\hline 南头镇 & 家电 & 电子信息工程 \\
\hline
\end{tabular}

\section{2 创新专业管理机制, 激发专业建设活力}

如果说专业布局体现了高职院校的决策力, 那么专业建设与发展则是考验高职院校的执 行力。专业主任负责制是在 “一镇一品一专业” 专业布局下催生的专业管理创新机制。专业 主任负责制采用竞聘上岗的竞争机制, 使有企业工作经验、有管理能力和创新能力的年轻教 师脱颖而出担任专业主任。

在专业主任负责制下，学院与专业主任签订专业建设与发展责任状，专业主任对本专业 的建设与发展负责。专业主任负责日常教学、专业与企业互动合作、团队建设、社会服务、 学生实习就业等各项工作; 专业主任负责制给予专业主任在专业才队建设中更大的自主权, 专业主任对本专业师资具有选聘权、支配权和考评权; 专业主任与相关企业定期交流互动, 开展校企专业共建。

专业主任负责制使专业建设责任明晰化，促进了专业与企业的对接。首先，促使专业教 师成为具有企业思维、企业精神和企业行为的教学团队; 其次, 打破了传统课程体系, 建立 由企业、行业技术人员与专业教师合作构建的基于工作过程与岗位需求的课程体系; 第三, 打破了教材 “闭门造车” 的编写模式, 由企业一线技术人员与专业教师编写基于工作过程的 项目化教材; 第四, 打破了专业教学 “课堂化” 格局, 用企业项目开展教学。

\section{3 启动科技创新引擎, 全面提升服务能力}

为了解决企业科技创新的难题, 学院筹建了中山市自动化研究所、中山市现代制造技术 研究所等八个研究所。通过研究所开展企业技术攻关, 新技术推广, 产品研发, 市场拓展及 校企横向科研课题研究等产学研深度合作; 学院引进现代服务业协会、物流协会等17家行业 协会进驻学院, 加强系部各教研室与对应的行业协会联系, 通过专业研室与行业协会互动合 作，促进专业建设和人才培养; 学院制定“政校企”合作专干、科技特派员“驻镇”计划, 通过 派遣专业教师深入各专业镇, 了解企业需求、传递合作意向、联手企业开展科技攻关、技术 创新, 改进生产工艺, 协助镇区政府开展区域经济发展战略研究等工作。

\section{4 启动科技创新引擎, 全面提升服务能力}

专业对接专业镇的布局与建设不但使专业镇在人才、技术、创新等方面有了很大的改善, 同时也促使高职服务专业镇的能力和水平大大提升。然而专业镇转型升级所要求的技术创新 不断催生专业融合与重组, 高职服务能力的进一步提升有赖于专业的跨界组合与集群发展。 为满足中山产业发展以灯饰光源、装备制造、纺织服装等传统产业集群为重点的发展需求, 中山职业技术学院产业学院应用而生。 


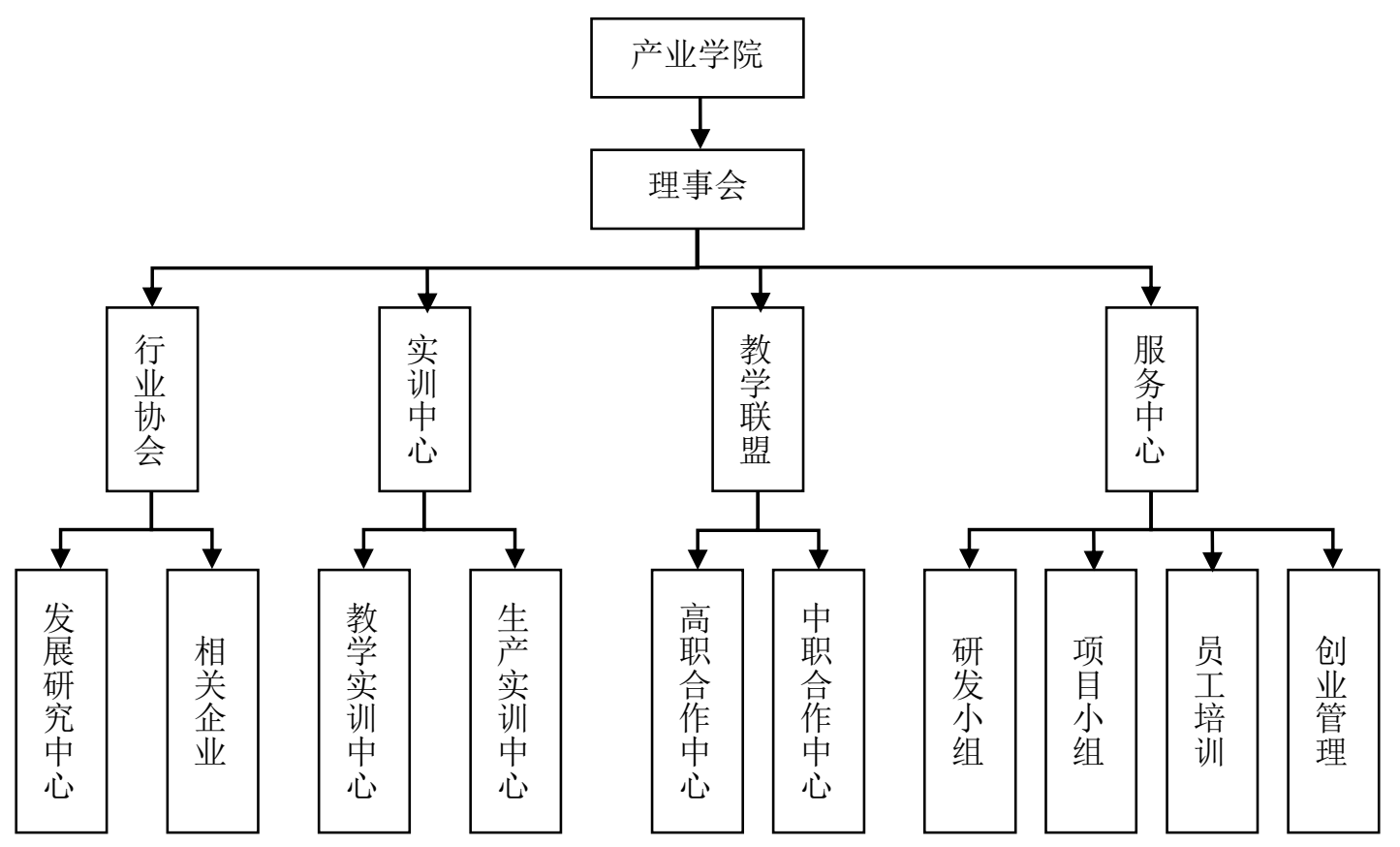

图2 电梯学院组织结构图

中山职业技术学院产业学院完全根据中山专业镇和产业发展创建, 以电梯学院为例: 电 梯学院办学基地设在中山市南区国家级电梯产业基地, 学院采用理事会领导下的院长负责制, 以政府、行业、学校三方为主要发起人, 吸收国内骨干企业参加成立电梯学院理事会, 制定 理事会工作章程, 确定电梯学院管理架构, 电梯产业学院组织结构如图2所示。中山市南区政 府负责场地建设和部分教学科研设备的投入; 学校将现有电梯专业的人员和实训设备全部并 入电梯学院, 并负责电梯学院的日常教学管理工作; 产业学院与行业、研发机构合作, 构建“产 学研”新型教学实验区, 教学模式采用基于工作过程的模块化教学。

根据专业、产业发展需要, 学院还将沙溪服装产业学院建在中国休闲服装专业镇创意园 区, 将灯饰产业学院建在中国灯饰之都古镇镇。产业学院的建设使专业建设逐渐由外延扩展 转向内涵拓展, 进一步提高专业结构与产业结构的啮合度, 推动产业价值链向高端延伸。产 业学院建在专业镇进一步加强了学校与企业合作、交流, 实现资源整合共享, 提高科技成果 转化率, 促进集群企业的规模发展。

\section{4. 结束语}

高职教育是服务区域经济发展的主力军, 高职院校人才培养与社会服务要找到准确的着 力点, 同时要通过政府、企业协同创新发展, 不断提高人才培养水平和社会服务质量。总之, 高职院校只有充分调研区域经济发展需求, 正确定位学校发展方向, 创新办学模式, 才能使 全面提升办学质量和水平。

\section{致谢}

本文为国家社科基金一般项目《政府有效介入下的职业教育校企合作长效机制研究》(课 题批准号：BJA120081)和广东省教育科学“十二五”规划课题《基于第三方评价的高职教育人 才培养质量反馈系统的构建研究》（项目编号：2012JK334）的阶段性成果之一。

\section{References}

[1] "Global Value Chains Meet Innovation System: Are there learning opportunities for developing countries?". C.Pietrobelli, R.Rabellotti. World Development. 2011 
[2] Conceptualising Cluster Evolution: Beyond the Life-Cycle Model?. Martin R, Sunley P. Papers in Evolutionary Economic Geography. 2011

[3] Governance and upgrading: Linking industrial cluster and global value chain research. Humphrey J, Schmitz H. IDS Working Paper No.120. 2000

[4] "The Impact of Operating in Multiple Value Chains for Upgrading: The Case of the Brazilian Furniture and Footwear Industries". Lizbeth Navas Aleman. World Development. 2011

[5] Lujuan Shen: Research on Interaction of Higher Vocational Education and Regional Industrial Structure [J] Vocational Education Forum, 2010(21):11-13.

[6] Genrang Zheng: Giving Full Play to the Advantages of Regional Industry and Expanding the Field of Vocational Education Cooperation [J].Vocational and Technical Education in China, 2006(5):18-20.

[7] Wei Fan: Specialty is the Brand and Soul of Higher Vocational School [N].China Youth Daily, 2012-2-27(11).

[8] Nianyou Chen, Changqing Zhou, Zhuping Wu: Connotation and Realization of the Integration of Industry and Education [J].Chinese University Science and Technology,2014,8:40-42.

[9] Qinghua Wu: Enhancing the Ability of Industry Guidance and Deepening the Integration of Industry and Education in Vocational Education [J]. Vocational and Technical Education in China, 2014, 21:155-158. 